\title{
Changes in Antipsychotic Medication in Clients of Assertive Community Treatment in Japan: A One-Year Follow Up
}

\author{
Naoko Satake ${ }^{1}$, Kyoko Hazama $^{2}$, Tamaki Sono ${ }^{*, 3}$, Makoto Takahashi $^{4}$, and Junichiro Ito ${ }^{4}$ \\ ${ }^{1}$ Department of psychiatry, Kohnodai Hospital, National Center for Global health and Medicine, 1-7-1 Kohnodai, \\ Ichikawa, Chiba, Japan \\ ${ }^{2}$ Graduate School of Education, Chiba University, 1-33 Yayoi-cho, Inage-ku, Chiba, Japan \\ ${ }^{3}$ Psilocybe Inc., 237 Sano, Higashi-Ohmi, Shiga, Japan \\ ${ }^{4}$ Department of Psychiatric Rehabilitation, National Center of Neurology and Psychiatry Japan, 4-1-1 Ogawahigashi- \\ cho, Kodaira, Tokyo, Japan
}

\begin{abstract}
The purpose of the present one-year follow-up study was to describe and investigate the change in the amount of antipsychotic drugs prescribed for ACT (assertive community treatment) clients in Japan. Subjects were 52 clients of ACT from January 2009 to December 2009. Prescription data were collected each month from the time the clients entered into ACT. The results of a Wilcoxon signed-rank test show that the dosage of antipsychotics significantly decreased from $1,131.3 \mathrm{mg}$ to $731.3 \mathrm{mg}$ over the course of the 12 months $(Z=-2.505, \mathrm{p}=0.012)$.
\end{abstract}

Keywords: Antipsychotics, Assertive Community Treatment, Medication, Japan, Schizophrenia, Community.

\section{INTRODUCTION}

High-dose treatments of antipsychotic drugs are not safe because they may cause cardiac arrest and even sudden death [1]. Moreover, treatment with atypical antipsychotics may increase the risk of metabolic syndrome and diabetes. Metabolic syndrome often encompasses medical conditions such as weight gain, hypertriglyceridemia, and increased insulin, glucose, and low-density lipoprotein cholesterol levels [2]. Polypharmacy of antipsychotics also can have clear adverse consequences, including early death [3]. Although the importance of simplifying prescriptions has been recognized, polypharmacy for schizophrenia patients remains prevalent [4].

Due to Japan's long history with a national health insurance system, Japanese patients are usually referred to psychiatric hospitals rather than community treatment. The duration of hospitalization in Japan is generally long and psychiatrists often prescribe multiple antipsychotic drugs. This form of polypharmacy results in higher doses because of the additive effects of two or more antipsychotic drugs prescribed concurrently[5].

Assertive community treatment (ACT) is a welldocumented, evidence-based case management program [6]. ACT provides a highly individualized and comprehensive array of services with integrated medical and rehabilitation services delivered by an interdisciplinary team in the community. In May 2003, the first experimental adoption of

*Address correspondence to this author at the 237 Sano, Higashi-Ohmi, Shiga, 521-1222, Japan; Tel: +81-90-6136-8580; Fax: +81-748-42-2695; E-mail: hello@ tamakisono.jp
ACT was initiated in Chiba, Japan [7, 8]. Considering the high doses of antipsychotic drugs prescribed concurrently in Japan, it is important to evaluate the change in antipsychotic medication for clients of ACT.

The purpose of the present one-year follow-up study was to describe and investigate the change in the amount of antipsychotic drugs prescribed for ACT clients.

\section{METHODS}

\section{Subject}

Study subjects were clients of ACT from January, 2009 to December, 2009. Of the 60 clients of ACT on December 31, 2009, 52 had entered into ACT before January 1, 2009. All 52 clients gave written informed consent to participate in the research.

\section{Setting}

The ACT program in this study is operated in a suburban area near Tokyo. The similarity of the ACT program to the original ACT model was measured by the Dartmouth Assertive Community Treatment Scale (DACTS) [9]. The DACTS consists of 28 items on a 5-point Likert scale with higher scores indicating higher similarity. The average ACT program score for January, 2010 was 4.3. Thus, this appears to be a well-implemented program that is in line with international standards.

The Research Ethics Board of the International Medical Center of Japan approved this study.

\section{Prescription Data}

Prescription data were collected each month beginning when the clients entered into ACT and ending 12 months 


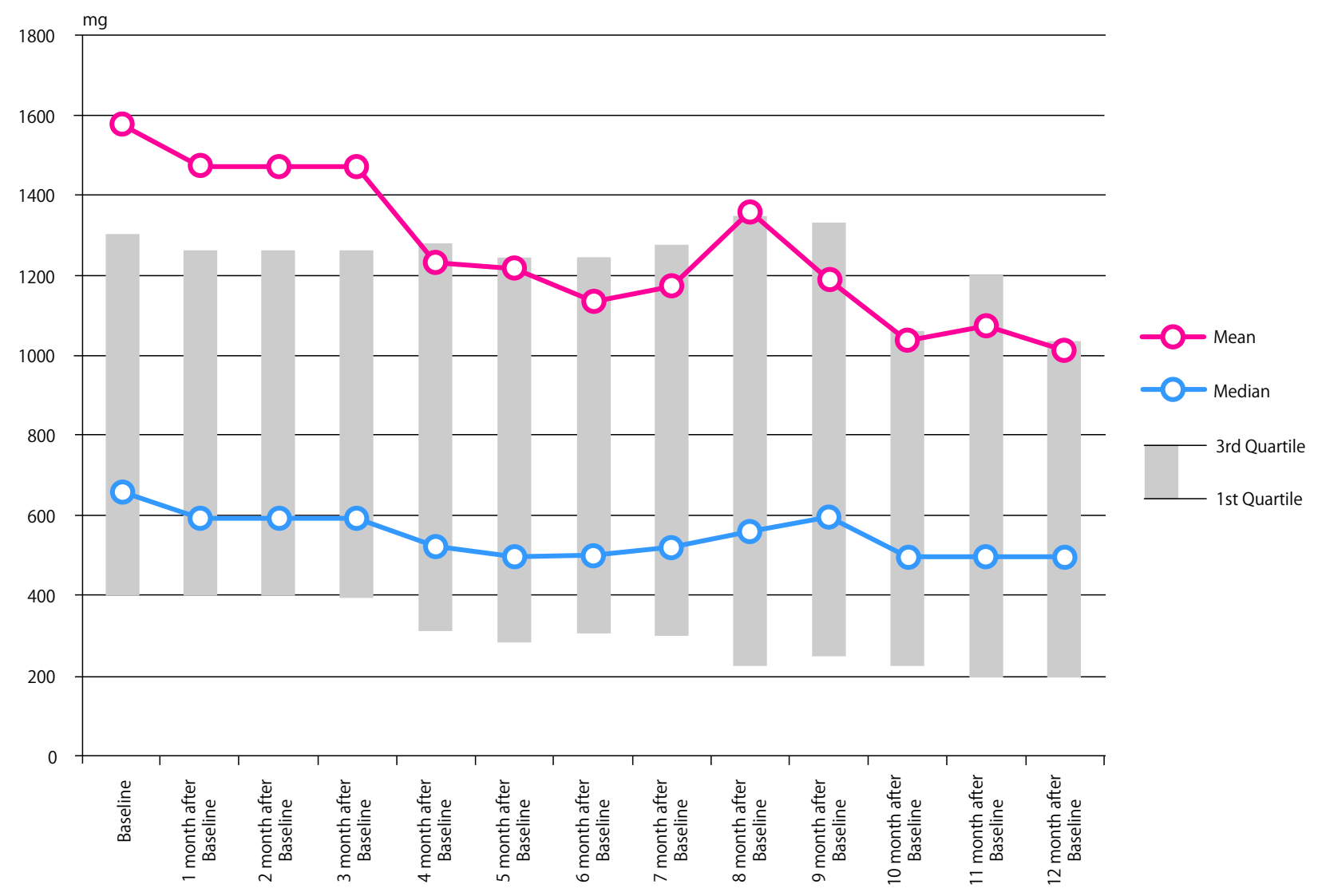

Fig. (1). Change of dosage of antipsychotics (CPZeq).

after entry. The average daily dose was established for each antipsychotic medication and converted to the relative potency equivalent of $100 \mathrm{mg}$ of chlorpromazine (CPZeq). Doses equivalent to $100 \mathrm{mg}$ /day of chlorpromazine were 2 $\mathrm{mg}$ /day for risperidone and $5 \mathrm{mg} /$ day for olanzapine. These, and the equivalencies of other antipsychotic medications, were based on information published in the literature [10, 11]. Polypharmacy was defined as the co-prescription of two or more antipsychotic medications.

\section{Statistical Analysis}

Because the variances of CPZeq were skewed, a Wilcoxon signed-rank test was utilized to compare them between the baseline and 12 months after baseline. Statistic calculations were performed using PASW 17.0.

\section{RESULTS}

The average age of subjects was $44.7(\mathrm{SD}=11.7)$ years; $48.1 \%$ of clients were male. Psychiatric diagnoses included schizophrenia or a related disorder (39 clients, or $75.0 \%$ ), affective disorders or a related disorder (8 clients, or 15.4 $\%$ ), and other disorders (5 clients, or $9.6 \%$ ). The average number of hospitalizations before participation in ACT was $4.3(\mathrm{SD}=3.2)$. The average length of time clients served in ACT was 36.7 months $(\mathrm{SD}=21.7)$ and 32 out of $52(61.5 \%)$ clients had no experience of admission to the hospital during this period.

Fig. (1) shows the mean, median, and first and third quartiles for the total dosage of antipsychotics received each month between baseline and 12 months after baseline. The total dosage of antipsychotics decreased over the year during which the study took place. The results of the Wilcoxon signed-rank test show that the dosage of antipsychotics significantly decreased from $1131.3 \mathrm{mg}$ to $731.3 \mathrm{mg}(\mathrm{Z}=$ $-2.505, \mathrm{p}=0.012$ ) over the course of the 12 months.

The results of the Chi square test showed that the number of clients who were receiving dosages of antipsychotics above $1000 \mathrm{mg}$ was significantly decreased from $21(40.4 \%)$ at baseline to $14(26.9 \%)$ at 12 months after baseline (Chisquare $=16.4, \mathrm{p}<.001)$.

At baseline, 27 (54.0\%) of the 50 clients were prescribed polypharmacy and at 12 months after baseline $30(60.0 \%)$ clients were prescribed polypharmacy. In terms of prescription patterns, there was no significant difference between these two periods.

\section{DISCUSSIONS}

The dosage of antipsychotic drugs for clients of ACT significantly decreased one year after they had been referred to an ACT team. Excessive dosing refers to doses greater than the optimal daily dosage of $1000 \mathrm{mg}$ of chlorpromazine or the equivalent of another antipsychotic [12]. The results showed that the number of clients who received excessive doses was also significantly decreased. These decreases were made possible by the intensive and integrated care of ACT as well as the close communication between the prescriber and the case managers who monitor clients' daily living in the community setting. 
These results should be cautiously interpreted because there are limitations. A major limitation is the lack of control groups and the fact that clinical outcomes of the treatment, such as clients' symptoms, QOLs, social functioning, or other outcomes, were not evaluated. It is difficult to determine whether the reduction of the dosage of antipsychotic drugs were due to the ACT intervention or some other cause. However, previous results show that ACT effectively reduced the costs of hospital care, while improving outcomes and client satisfaction for people with severe mental illnesses $[6,7]$. We suggest that the reduction of antipsychotic drug dosage did not bring about adverse effects for clients. Because we only measured subjects in one ACT program, generalization of these findings is limited; however, ACT programs share a common structure of services based on internationally disseminated standards, and it is possible to apply the findings of this study to other ACT programs.

In conclusion, the present study demonstrated a reduction in antipsychotic drug dosage for ACT clients in Japan. We suggest that ACT could have a positive influence for clients trying to recover in the community without an excessive amount of antipsychotic drugs.

\section{ACKNOWLEDGEMENTS}

The authors declare that they have no competing interests. NS and KH planned research. NS and MT acquired data. TS analyzed, interpreted data, and drafted the manuscript. JI managed the research project. All the authors read and approved the final manuscript.

\section{REFERENCES}

[1] Glassman AH, Bigger JT. Antipsychotic drugs: Prolonged qtc interval, torsade de pointes, and sudden death. Am J Psychiatry 2001; 158: 1774-82.

[2] Lieberman JA. Metabolic changes associated with antipsychotic use. Prim care companion. J Clin Psychiatry 2004; 2(Suppl 2): 813.

[3] Waddington J, Youssef H, Kinsella A. Mortality in schizophrenia. Antipsychotic polypharmacy and absence of adjunctive anticholinergics over the course of a 10-year prospective study. Br J Psychiatry 1998; 173: 325-9.

[4] Bitter I, Chou J, Ungvari G, et al. Prescribing for inpatients with schizophrenia: an international multi-center comparative study. Pharmacopsychiatry 2003; 36(4): 143-9.

[5] Chong MY, Tan CH, Fujii S, et al. Antipsychotic drug prescription for schizophrenia in East Asia: rationale for change. Psychiatry Clin Neurosci 2004; 58(1): 61-7.

[6] Marshall M, Lockwood A. Assertive community treatment for people with severe mental disorders. Cochrane Database Systemat Rev (Online) 2000(2): CD001089.

[7] Horiuchi K, Nisihio M, Oshima I, Ito J, Matsuoka H, Tsukada K. The quality of life among persons with severe mental illness enrolled in an assertive community treatment program in Japan: 1year follow-up and analyses. Clin Pract Epidemol Ment Health 2006; 2: 18.

[8] Ito J, Oshima I, Nishio M, et al. The effect of assertive community treatment in Japan. Acta Psychiatr Scand. (in press).

[9] Teague GB, Bond GR, Drake RE. Program fidelity in assertive community treatment: development and use of a measure. Am J Orthopsychiatry 1998; 68(2): 216-32.

[10] Honer WG, Thornton AE, Chen EY, et al. Clozapine alone versus clozapine and risperidone with refractory schizophrenia. N Engl $\mathrm{J}$ Med 2006; 354(5): 472-82.

[11] Inagaki A, Inada T, Fujii Y. Equivalent Dose of Psychotropics. Toyko: Seiwa Shoten 1999.

[12] Lehman AF, Steinwachs DM. Translating research into practice: the Schizophrenia patient outcomes research team (PORT) treatment recommendations. Schizophrenia Bull 1998; 24(1): 1-10.

Received: August 24, 2010

Revised: October 16, 2010

Accepted: October 27, 2010

(c) Satake et al.; Licensee Bentham Open.

This is an open access article licensed under the terms of the Creative Commons Attribution Non-Commercial License (http://creativecommons.org/licenses/by-nc/3.0/) which permits unrestricted, non-commercial use, distribution and reproduction in any medium, provided the work is properly cited. 